\title{
Improvement of the Quality of Cotton Fabric Through Functionalization of Tagetes minuta (TaMi) Dye
}

\author{
Isemeki J. Owino $^{1 *} \quad$ Leonidah K. Omosa $^{1} \quad$ John M. Onyari ${ }^{1}$ Francis J. Mulaa $^{2}$ \\ Richard K. Mibey ${ }^{3}$ \\ 1.Department of Chemistry, University of Nairobi, P. O. Box 30197-00100, Nairobi, Kenya \\ 2.Department of Biochemistry, University of Nairobi, P. O. Box 30197-00100, Nairobi, Kenya \\ 3.Department of Botany, University of Nairobi, P. O. Box 30197-00100, Nairobi, Kenya
}

\section{The research is financed by DAAD and WFS}

\begin{abstract}
Non-functionalized and functionalized Tagetes minuta (TaMi) dye obtained using methanol and water showed varied fastness onto cotton fabric. Furthermore, HPLC profile of the methanol dye showed more peaks and hence was expected to be richer in secondary metabolites that impacted on the quality of the dye. This was confirmed from the IR spectrum which showed more functional groups from this dye as compared to the water dye. The functionalized methanol dye exhibited good fastness onto cotton textile and minimal bleaching effects, as compared to non-functionalized $\mathrm{H}_{2} \mathrm{O}$ and $\mathrm{MeOH}$ dye. Furthermore, the process involved the use of low quantities of the dye material/solution as compared to non-functionalized dye, hence resulting to less impact on environmental degradation. The colors of the textiles produced from the methanol functionalized dye were highly resistant to fading or running. The cotton fabric articles that were tri-mordanted at $80-90{ }^{\circ} \mathrm{C}$ and dyed using the functionalized dye exhibited uniform absorption of color of the dye and good fastness. Functionalization of the methanol TaMi dye was obtained by the reaction of the TaMi dye with 1,4-butanediol diglycidyl ether (BDDE). The alum tri-mordanted textile materials produced brighter colors of brown as compared to the singly alum mordanted fabrics. This is due to the tannin factor in tri-mordants that led to the brightening effect. Furthermore, longer duration of time for tri-mordanting might have had a greater impact to the brightness effect. Additionally, characterization of the dye obtained using the two solvents was done using HPLC and IR. The formed functionalized dye has many applications as colorants in textiles, paints, inks, plastics, cosmetic articles and electronic materials.
\end{abstract}

Keywords: Cotton fabric, Tagetes minuta, dye, functionalized, 1,4-butanediol diglycidyl ether, colorants

DOI: $10.7176 / J N S R / 11-16-02$

Publication date:August $31^{\text {st }} 2020$

\section{Introduction}

1.1 TaMi dyes

TaMi dye is a natural dye from a plant known as Tagetes minuta, which is also known as Inabutsaka in Luhya ${ }^{[1]}$. The pounded leaf infusion of this plant is traditionally used as an insecticide against disease vectors for both human beings and domestic animals including; mosquitos and fleas among others. This herb grows naturally in various parts of the country as a weed. In 2009, Mibey et al from Moi University discovered the use of this plant, which is also a stubborn weed, as a natural dye applied mainly onto cotton fabric which is currently being used in Rivatex textile industry, Kenya ${ }^{[2]}$. The discovery of this natural and easily available dye has led to reduction on costs of importing synthetic dyes from South Africa and India for Rivatex industry. Furthermore, this dye is natural and environmentally friendly unlike the other chemical based dyes. Currently, the TaMi Dye is applied to the cotton fabric through adsorption involving the use of large amounts of dye and excessive solvents making it costly to treat the resultant effluent before release to the environment.

T. minuta has previously been known to elaborate various classes of compounds including; essential oils, thiophenes, flavonoids and phenolic compounds ${ }^{[3-10]}$. These compounds, which constitute the dye molecules, are expected to interact with the cotton fabric to improve on the dye retention.

\subsection{Functionalization of natural dyes}

Functionalization is the procedure of adding new functionalities, capabilities, properties or features to a particular material by altering its surface chemistry ${ }^{[11]}$. It can take place on the nanoparticles of a metal as well as a metal oxide to help in stabilizing such nanoparticles or there can be a C-H functionalization whereby an $-\mathrm{H}$ atom of $-\mathrm{C}$ $\mathrm{H}$ bond is substituted by a functional group ${ }^{[12-13]}$.

There are numerous benefits that are achieved by the use of functionalized dye over the conventional techniques. The use of functionalized dye in textile coloration usually results to good fastness onto fabric that leads to reduction in environmental pollution as compared to the traditional dyeing methods. The release of wastewater is unavoidable in both cases, but it is largely reduced and the post-treatment cost of the colored waste solvent is also minimized ${ }^{[14]}$. 
In the current study, the $\mathrm{MeOH}$ dye was functionalized using 1,4-butanediol diglycidyl ether (BDDE) which is one of the common cross linking agent used in the dyeing industry towards improving the fastness of the dye onto fabric. BDDE is capable of reacting with functional groups such as; amines, sulphydryl and hydroxyls groups to form secondary amines, ether or thioether bonds, respectively. It is used for the preparation of amylose, hydroxyethyl-cellulose and xylan and for cross linking polyethylenimine as well as hyaluronic acid into hydrogels. Amine or hydroxyl containing bis-epoxy supports are also mainly reacted with BDDE to produce particles that contain terminal epoxide group for mainly immobilization reactions ${ }^{[15]}$.

\subsection{Interactions of dyes with fabric material}

In most dyeing processes, the dye molecules are consistently linked to a variety of fabric material through both physical and chemical interactions towards incorporating dye molecules inside the fiber microstructure ${ }^{[16]}$. In some cases, the dye molecules can be fastened firmly by covalent bonds through chemical reactions with the fiber. Other dye-fiber intermolecular forces of attractions are weaker and include; hydrogen bonding, Van Der Waals forces of attraction and ionic bonding. Whereas a number of dyeing techniques have many steps, a lot of the dyes can simply be applied by submerging the cotton fabric into an aqueous dye solution; this is termed as direct dyes. In many other situations, auxiliary compounds as well as additional steps are needed in obtaining the desired fastness ${ }^{[17]}$ as is the case in the current study where BDDE was introduced to improve on the retention of the dye onto the fiber. In most cases, the fiber structure from where the common fabrics are produced offers some direction for the selection of suitable colorants in dyeing.

\section{Experimental}

\subsection{Collection and preparation of plant materials}

Tagetes minuta plant was identified from different farms in Eldoret town by the help of a taxonomist. The inflorescence parts of the T. minuta plant were collected from maize farms in Kapseret and Kipkaren areas, and farms next to the Rift Valley Textile Factory (Rivatex) in Eldoret, Kenya (GPS Coordinates of $0^{\circ} 30^{\prime} 51.3972^{\prime \prime} \mathrm{N}$ and $35^{\circ} 16^{\prime} 11.2044^{\prime \prime}$ E) as shown in Figure 1. For optimal yield of the dye material, only mature inflorescence parts of the plants were harvested ${ }^{[2,18-19]}$.

\section{Google Maps Kapseret Shopping Center, C39, Eldoret to Kipkaren Drive 28.9 km, 48 min}

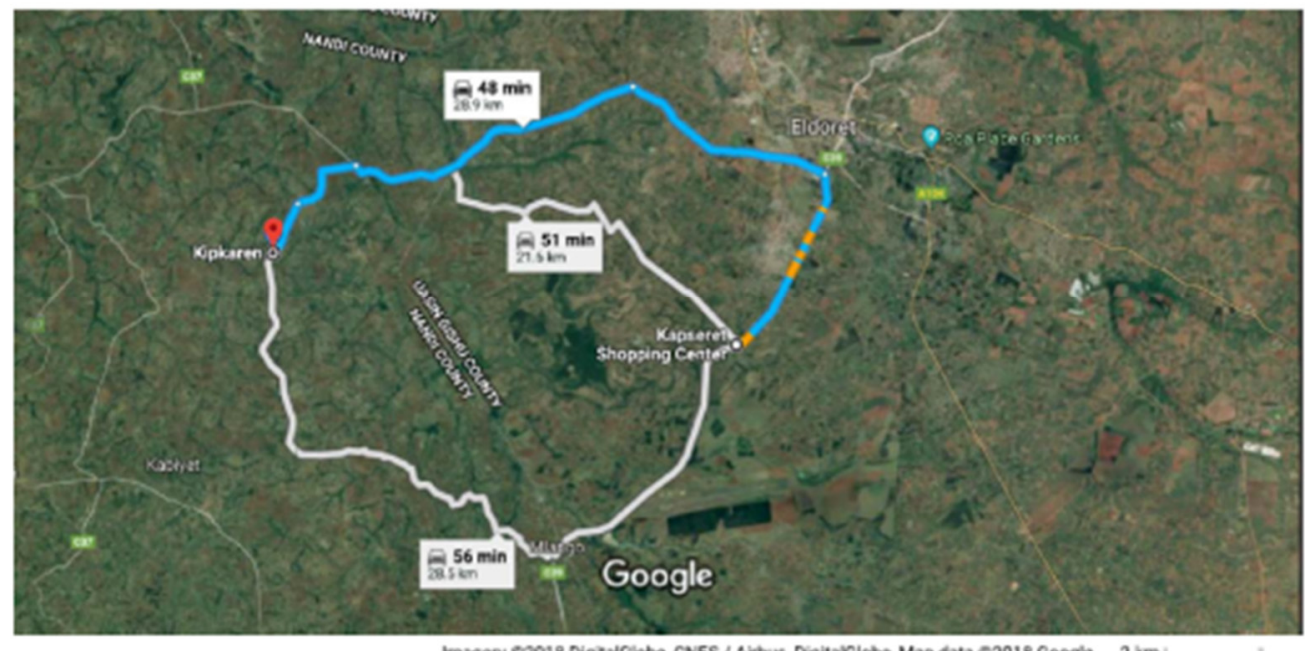

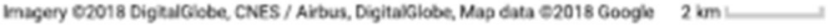

Figure 1. Google map of sampling site, Kenya

\subsection{Preparation of methanol and water dye solution}

Briefly, $50 \mathrm{~g}$ of the ground plant material were soaked in $1.25 \mathrm{~L}$ of methanol for 24 hours and the obtained dye bath was stirred and let to settle before straining ${ }^{[20]}$. Similarly, the water dye solution was obtained by soaking 100 $\mathrm{g}$ of the ground plant material in $2.5 \mathrm{~L}$ of water and simmered for $2 \mathrm{~h}$. The obtained dye bath was allowed to cool before straining the resultant solution ${ }^{[2,21]}$.

\subsection{Functionalization of the dye using $B D D E$}

The functionalized dye was prepared by mixing $10 \mathrm{~mL}$ of 1,4-butanediol diglycidyl ether (BDDE) and $100 \mathrm{~mL}$ of methanol dye solution 


\subsection{Preparation of fabric for the dyeing process}

Bleached cotton fabric articles (white cloth) ${ }^{[22]}$ from Rivatex were cut into small and uniform sizes. Fabric scouring was achieved in accordance to procedures modified by Samanta and Konar (2011) and Wipplinger, $(2005)^{[20,23]}$ while single mordanting was effected using alum ${ }^{[24]}$ and trimordating using alum, tannin and finally alum ${ }^{[2,24-25]}$.

\subsection{Fabric dyeing}

The mordanted materials were added separately to the three dye baths, which include; the $\mathrm{H}_{2} \mathrm{O}(500 \mathrm{~mL}), \mathrm{MeOH}$ $(500 \mathrm{~mL})$ and $\mathrm{MeOH}$ and BDDE dye baths $(500 \mathrm{~mL})$. The water dye bath was heated and simmered for $1 \mathrm{~h}$ at 80 $90{ }^{\circ} \mathrm{C}$ then removed from the source of heat and allowed to cool. The articles were later washed in warm water to prevent fabric shocking and causing of felting to take place ${ }^{[17]}$. For effective dyeing, the $\mathrm{MeOH}$ and $\mathrm{MeOH}-\mathrm{BDDE}$ dye baths were left for $24 \mathrm{~h}$ for the process to come to completion. The fabric articles were then removed and rinsed with the respective solvents used for dyeing.

\subsection{Fastness test to washing}

A soap solution free from fluorescent brightening agents composed of $5 \mathrm{~g}$ of Menengai bar soap and $2 \mathrm{~g}$ of anhydrous sodium carbonate $\left(\mathrm{Na}_{2} \mathrm{CO}_{3}\right)$ in $1 \mathrm{~L}$ of distilled water was prepared in a container and heated to $60{ }^{\circ} \mathrm{C}$. Samples of dyed cotton fabric articles measuring $10 \mathrm{~cm}$ x $5 \mathrm{~cm}$ were placed in a container, and continuously stirred for 30 minutes while maintaining a balanced heating at $60{ }^{\circ} \mathrm{C}$. The articles were removed and rinsed in running cold water for 10 minutes $^{[26]}$ and then wrung and air dried in the environment with a temperature not exceeding $60{ }^{\circ} \mathrm{C}$.

\subsection{Bleaching test on dyed fabrics}

The dyed fabric pieces were immersed into a 3.85\% (v/v) sodium hypochlorite $(\mathrm{NaOCl})$ solution and left to stand for a duration of $1 \mathrm{~h}^{[27]}$. The fabrics were then removed from the bleaching solution, squeezed and washed in running tap water at room temperature to help in observing the effect of the bleaching solution.

\subsection{Characterization of $\mathrm{MeOH}, \mathrm{H}_{2} \mathrm{O}$ and $\mathrm{MeOH}$ functionalized dyes}

Characterization of the functional groups of the $\mathrm{MeOH}, \mathrm{H}_{2} \mathrm{O}$ and $\mathrm{MeOH}$ functionalized dye solutions was done using IR spectra in accordance with Wahl (1990) procedure ${ }^{[28]}$. IR spectra of the liquids were obtained by dissolving the dye samples in an IR transparent solvent, $\mathrm{CCl}_{4}$. The dye solutions were dried in an oven at $105^{\circ} \mathrm{C}$ and then the solid spectra was obtained by mixing the prepared solid with dry $\mathrm{KBr}$. This was done by grinding into fine and well mixed powder, and then a disk of the mixture was formed under high pressure. The $\mathrm{KBr}$ disk was used to produce an IR spectrum that was free of nearly all unimportant peaks. For the $\mathrm{H}_{2} \mathrm{O}$ and $\mathrm{MeOH}$ functionalized solutions, approximately 1-2 drops of the solutions were each placed between two disks of pure $\mathrm{KBr}$ and the resultant 'sandwich' put directly in the spectrometer sample holder.

\subsection{HPLC analysis}

In order to determine the structural diversity of the dye solutions in terms of secondary metabolites, the HPLC profiles of the dye solutions were determined following the procedure by Raman (2016) ${ }^{[29]}$. Briefly, the dye solutions were mixed with $\mathrm{MeOH}$ and centrifuged at 10,000 RCF in an eppendorf vial. $500 \mathrm{uL}$ of the supernantant liquid was further centrifuged at 10,000 RCF to help collect the filtrate which was loaded into an HPLC machine for generation of spectrum.

\section{Results and Discussion}

\subsection{The TaMi dyestuff and dye solutions/baths}

A dark brown dye stuff was obtained after grinding the inflorescences parts of Tagetes minuta plant, resulting to dark brown dye solutions from the three solvents used: $\mathrm{MeOH}, \mathrm{H}_{2} \mathrm{O}$ and functionalized $\mathrm{MeOH}$.

\subsection{The dyeing process}

After the dyeing process on to cotton fabric, there were no substantial differences in terms of the colours of the cotton fabric as all the three dye solution resulted to dark brown fabrics with minimal differences in their shades. The fabric articles took up a brown color in the initial stages of the dyeing process for $\mathrm{H}_{2} \mathrm{O}$ and $\mathrm{MeOH}$ dye solutions. However, the textile turned light green with $\mathrm{MeOH}$ BDDE dye in the initial dyeing process but surprisingly also changed to dark brown when dry as was the case for the other two dye solutions. Fabric articles tri-mordanted and dyed at $80-90{ }^{\circ} \mathrm{C}$ showed uniform absorption of dye. Singly mordanted fabrics dyed at $80-90{ }^{\circ} \mathrm{C}$ showed no significant difference as compared to the tri-mordanted articles, apart from brightness. However, functionalized mordanted fabric articles had brighter shades that could have been attributed to other prevailing factors such as temperature and $\mathrm{PH}$ during the dyeing process. 


\subsection{Fastness test to cotton fabric}

The fastness test results showed that the cotton fabric dyed with $\mathrm{MeOH}$ dye solution containing BDDE had good fastness as compared to the other two cotton fabrics dyed with $\mathrm{H}_{2} \mathrm{O}$ and $\mathrm{MeOH}$ dye solutions. This could most probably be due to the reaction of the alcoholic and phenolic hydroxyl groups of the functionalized dye with the textile's cellulose-OH groups, which produced stronger cellulosic dyed fiber that do not easily fade away on washing with ordinary bar soaps.

\subsection{Bleaching test on dyed fabrics}

In the bleaching test, there was minimal effect of $\mathrm{NaOCl}$ on all the dyed fabric, both single and tri-mordanted fabrics, when immersed in concentrated bleaching solution for $1 \mathrm{~h}$. Thus the dyes are not easily bleached by ordinary bleaches.

\subsection{Characterization of $\mathrm{MeOH}, \mathrm{H}_{2} \mathrm{O}$ and $\mathrm{MeOH}$ Functionalized Dyes}

The IR spectrum of the $\mathrm{MeOH}$ dye solution showed more functional groups as compared to the $\mathrm{H}_{2} \mathrm{O}$ dye solution most probably due to the fact that this solvent is capable of extracting a wider spectrum of compounds, both nonpolar and polar as compared to the $\mathrm{H}_{2} \mathrm{O}$ extract that is likely to target only polar compounds. The functional groups that were characterized from this solution included; N-H stretch and $\mathrm{OH}$ stretch $(3300 \mathrm{~cm}-1)$ which could be attributed to alcoholic or phenolic compounds characteristic of this plant. The fact that this band is broad could be due to intra and intermolecular hydrogen bonding resulting from acidic hydrogen of -OH groups of this classes of compounds and $\mathrm{O}, \mathrm{N}$ and $\mathrm{F}$ heteroatoms from the same or other molecules. The alcoholic hydroxyl group is most likely attributed to the mono-, sesquiterpenoids and thiophenes that have previously been characterized from this plant and related species ${ }^{[4,6,7,10,20-32]}$, while the phenolic hydroxyl group could be due to the flavonoids and other phenolic compounds characteristic of Tagetes species ${ }^{[3,5,8,9,33]}$. Similarly, the $-\mathrm{C}-\mathrm{H}(2950 \mathrm{~cm}-1), \mathrm{C} \equiv \mathrm{C}(2350 \mathrm{~cm}-$ 1), $-\mathrm{C}=\mathrm{O}$ stretch and $\mathrm{C}=\mathrm{C}(1650 \mathrm{~cm}-1),-\mathrm{CH}_{2}$ bend and $\mathrm{CH}_{3}$ bend $(1450 \mathrm{~cm}-1)$, and $(1050 \mathrm{~cm}-1)$ could also be attributed to the presence of monoterpenoids, sesquitepenoids, thiophenes and side chains of flavonoids and phenols $^{[4,6,7,10,30-32,34]}$. The -C-H aldehydic $(2850 \mathrm{~cm}-1)$ is most likely due to the sugar moieties of the flavonoid glycosides and aldehydes present in the genus Tagetes ${ }^{[9]}$. However, some functional groups such as the nitrile $\mathrm{C} \equiv \mathrm{N}$ $(2350 \mathrm{~cm}-1)$ and amine N-H stretch $(3300 \mathrm{~cm}-1)$ couldn't be accounted for based on previous phytochemical studies on plants on the genus Tagetes. Therefore, comprehensive phytochemical investigation of T. minuta need to be carried out towards accounting for all the functional groups identified through IR spectroscopy to also give guidance on the type of expected interactions with fabric fibers.

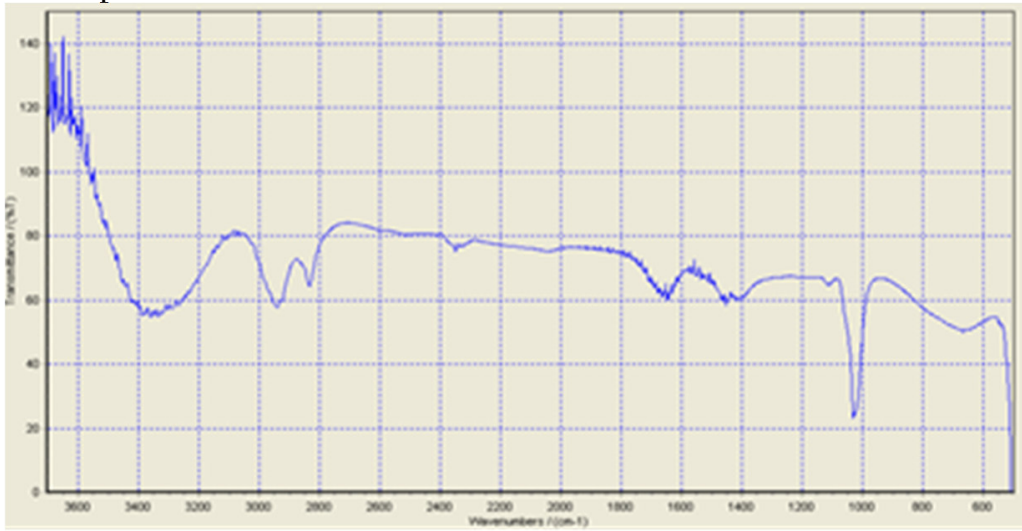

Figure 2. IR spectrum of methanol extract dye of Tagetes minuta

The IR spectrum of the $\mathrm{H}_{2} \mathrm{O}$ dye solution showed similar phytochemical profiles with the presence of the $\mathrm{OH}$ (3400 cm-1), $\mathrm{C} \equiv \mathrm{C}(2100 \mathrm{~cm}-1) \mathrm{C}=\mathrm{O}(1650 \mathrm{~cm}-1))$ and $\mathrm{CH}_{2}(1450 \mathrm{~cm}-1)$. This functional groups could be attributed to the presence of previously isolated phytochemicals from T. minuta species including; alcohols,

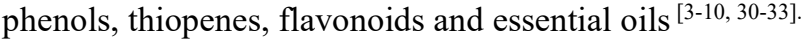




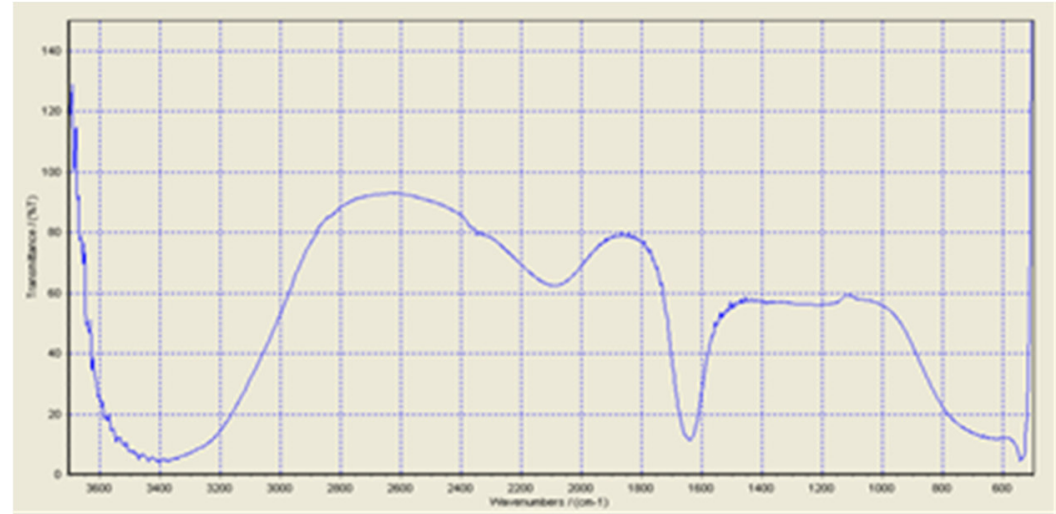

Figure 3. IR spectrum of the TaMi dye prepared from water

The functionalized dye solution exhibited all functional groups identified from the $\mathrm{MeOH}$ dye solution with extra functional groups assigned to alcoholic $\mathrm{C}-\mathrm{O}-\mathrm{H}$ bend at $1350 \mathrm{~cm}-1$, alcoholic $\mathrm{C}-\mathrm{OH}$ and ether $\mathrm{C}-\mathrm{O}-\mathrm{C}$ stretch appearing at $1020 \mathrm{~cm}-1,1100 \mathrm{~cm}-1,1200 \mathrm{~cm}-1,1250 \mathrm{~cm}-1$. As was the case for the $\mathrm{MeOH}$ dye solution, peaks characteristic of amides, amines and aliphatic nitro groups could not be accounted for based on previous phytochemistry of the Tagetes species.

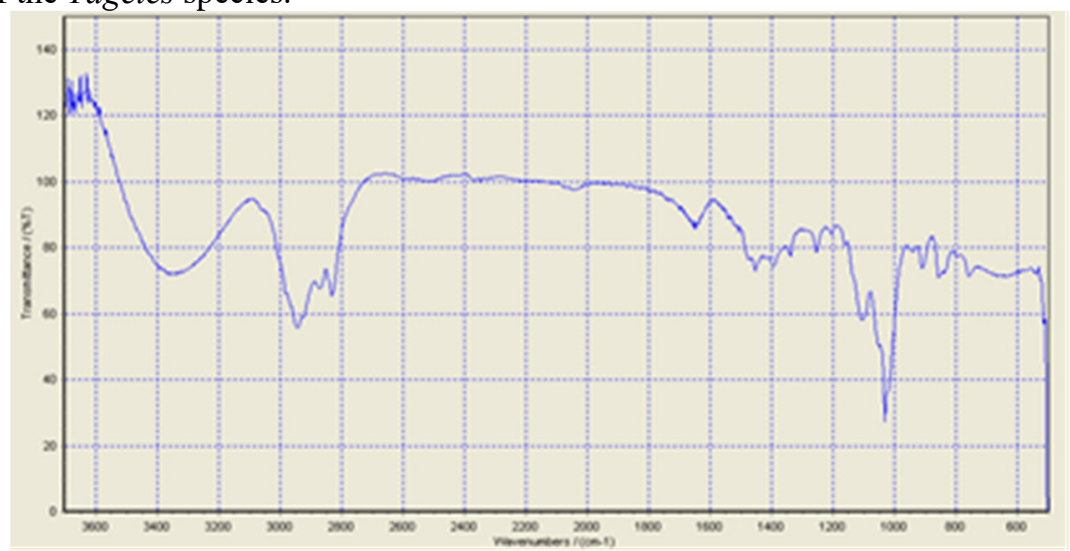

Figure 4. IR spectrum of methanol extract dye of Tagetes minuta reacted with BDDE

\subsection{HPLC Profiles}

The HPLC profiles of the $\mathrm{MeOH}, \mathrm{H}_{2} \mathrm{O}$ and $\mathrm{MeOH}$ functionalized dyes were similar based on the retention times of secondary metabolites expected in different dye solutions. Chromatographic HPLC retention times are characteristics of the compounds that they represent but were not unique as shown in Figures 5,6 and 7.

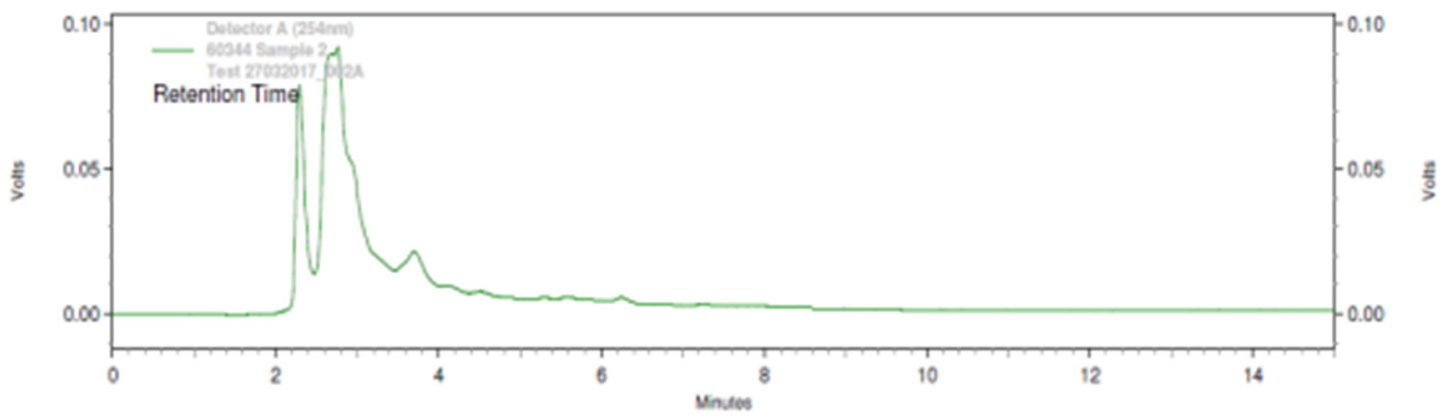

Figure 5. HPLC spectrum of methanol extract dye of Tagetes minuta 


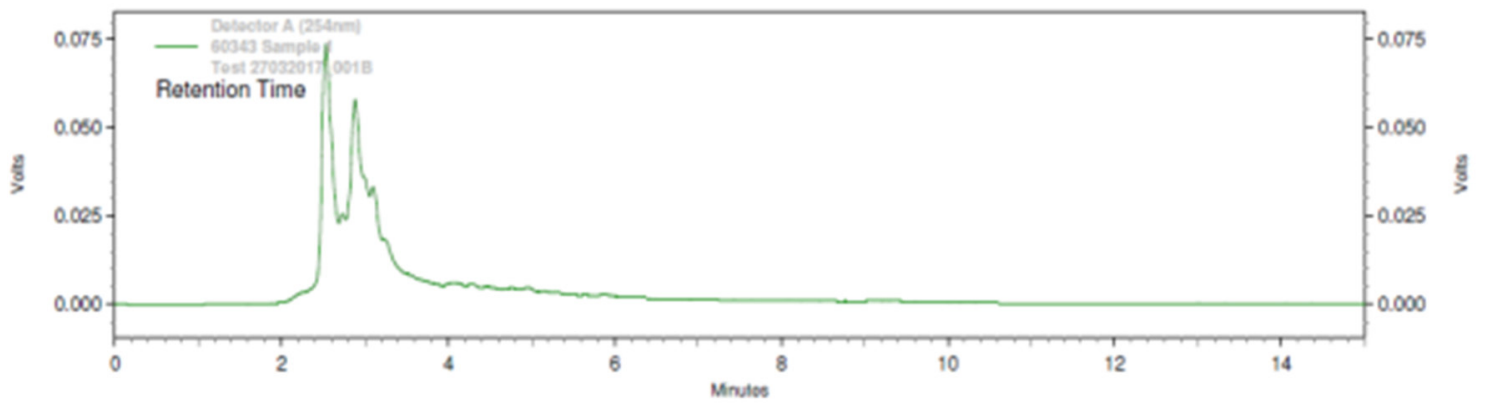

Figure 6. HPLC spectrum of the TaMi dye prepared from water

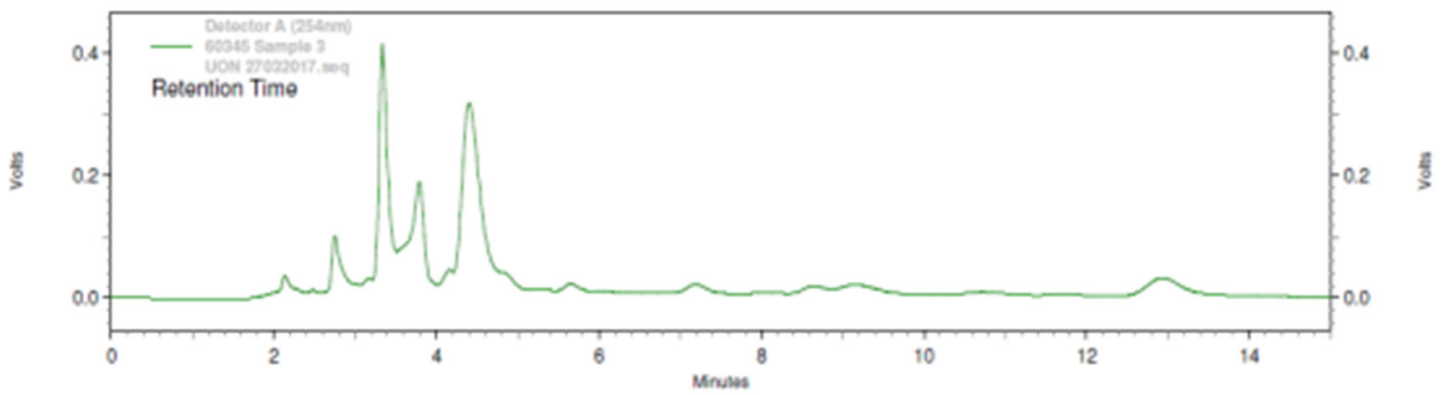

Figure 7. HPLC spectrum of methanol extract dye of Tagetes minuta reacted with BDDE

The HPLC profiles showed minimal difference in the retention times for constituent compounds found in $\mathrm{MeOH}$ and $\mathrm{H}_{2} \mathrm{O}$ with a greater diversity in classes of compounds found in the functionalized $\mathrm{MeOH}$ dye. This is most probably due to additional analoges resulting from the modification of the compounds such as the flavonoids and others using BDDE through cross-linking. The differences in the IR and HPLC spectra for the three dye solutions prove that functionalization of constituent phytochemicals with BDDE of the dye took place. This may have led to increased diversity of phytochemicals with the necessary functional groups to react with the functional $-\mathrm{OH}$ groups of the cotton fabric, thus forming fabric that does not easily fade away when washed with water using the normal soaps and detergents. Good color fastness of the resultant textile made the cotton fabric not to easily fade in the washing process ${ }^{[28,34-35]}$.

\section{Conclusion}

A brown methanol dye solution was prepared using methanol that was then functionalized using BDDE and characterized using HPLC and IR. The functionalized methanol dye produced dyed cotton fabrics with good fastness properties and minimal bleaching effects, thus improving the performance of the already known TaMi dye. Based on these considerations, since the dye gives good colors on cotton fabrics with required fastness and functional properties, it would be considered as a suitable dye that provides the major requirement needed for the textile processing industries, which include the garment unit ${ }^{[36]}$.

The results showed that plants are able to produce a viable dye that can be utilized for dyeing cellulose-based textiles. Tagetes minuta yields reactive dyes as demonstrated in the research study and supported by Trotman's (1970) standard testing procedures ${ }^{[26]}$. Nevertheless, diverse colors could be produced on the textiles depending on the type of mordant or combination of mordants being used in setting the colors onto the cotton fabrics. The study also revealed that a high temperature range of $80-90{ }^{\circ} \mathrm{C}$ are optimal for dyeing using water as the main solvent.

The alum tri-mordanted fabric pieces produced brighter colors of brown compared to the singly alum mordanted fabric articles. This is due to the tannin constituent in tri-mordanting that brought about a brightening result. Furthermore, longer duration of time in tri-mordanting might have had a greater impact to the brightness effect. All the dyed fabrics were observed to be bleached slightly by $3.85 \%$ (v/v) sodium hypochlorite using a spectro-guide instrument. This can be a significant attribute and it could be fairly suitable to dye protective garments with functionalized Tagetes minuta (TaMi) dyes ${ }^{[17]}$. Findings of the study points to the fact that dye extract from Tagetes minuta plant can be functionalized. This given study is thus a breakthrough in the dyeing industry since the world is looking for ways of protecting the environment from synthetic dyes. Furthermore, raw material from the plant ought to be easily available considering that they can effortlessly be propagated ${ }^{[37]}$. The plant's functionalized dye is a suitable renewable resource and thus has convincingly served the purpose of the project. 


\section{Acknowledgement}

I wish to thank the Almighty God for His protection all through the period of the research work. I wish also to express my sincere thanks to my supervisors: Prof. Leonidah Kerubo, Prof. Francis Mulaa and Prof. John Onyari, for their invaluable comments, skillful supervision and materials contributions, which enabled me to complete this research project. My sincere thanks and appreciation to Prof. Richard Mibey, the German Academic Exchange Service (DAAD), World Federation of Scientists (WFS), the Africa Centre of Excellence in Phytochemicals, Textile and Renewable Energy (ACEII-PTRE) at Moi University and all my colleagues in the laboratory, classmates and technical staffs in the Department of Chemistry and Biochemistry in University of Nairobi and Moi University for their kind cooperation, financial support and encouragement. I was greatly indebted to you all. Last of all, I wish to express my sincere thanks to my family members for their prayers and inspiration towards achieving this goal.

\section{References}

1. Kokwaro, J. (2009). Medicinal Plants of East Africa, $3^{\text {rd }}$ Edition, University of Nairobi Press, Pg 98

2. Mibey, K., Tuigong, R., and Makumba, N. (2009). Dyeing of cellulosic-based fabrics using dyes extracted from plant. East Afr J Sci, 2: 17-28.

3. Tripathi, A., Khan, S., Vaishnava, M., Gupta, K., and Singh, J. (1992). Compounds of taxonomic significance in Tagetes. Fitoterapia, 63: 85.

4. Singh, B., Sood, R. P., and Singh, V. (1992). Chemical composition of Tagetes minuta L. oil from Himachal Pradesh (India). J Essent Oil Res, 4: 525-526.

5. D'Agostino, M., De Simone, F., Zhong, L. Z., and Pizza, C. (1992). Flavonol glycosides from Tagetes elliptica. Phytochem, 31: 4387-4388.

6. Machado, M., Silva, M., Matos, F., Craveiro, A., and Alencar, J. (1994). The presence of indole as minor constituent of Tagetes erecta leaf oil. J Essent Oil Res, 6: 203-205.

7. Chalchat, J. C., Garry, R. P., and Muhayimana, A. (1995). Essential oil of Tagetes minuta from Rwanda and France: chemical composition according to harvesting location, growth stage and part of plant extracted. $J$ Essent Oil Res, 7: 375-386.

8. Guinot, P., Gargadennec, A., Valette, G., Fruchier, A., and Andary, C. (2008). Primary flavonoids in marigold dye: extraction, structure and involvement in the dyeing process. Phytochem Anal, 19: 46-51.

9. Gupta, P., and Vasudeva, N. (2012). A Potential Ornamental Plant Drug. Hamdard Med, 55.

10. Shirazi, M. T., Gholami, H., Kavoosi, G., Rowshan, V., and Tafsiry, A. (2014). Chemical composition, antioxidant, antimicrobial and cytotoxic activities of Tagetes minuta and Ocimum basilicum essential oils. Food Sci Nutr, 2: 146-155.

11. Chen, H., Schlecht, S., Semple, T. C., and Hartwig, J. F. (2000). Thermal, catalytic, regiospecific functionalization of alkanes. Science, 287: 1995-1997.

12. Godula, K., and Sames, D. (2006). CH bond functionalization in complex organic synthesis. Science, 312: 67-72.

13. Davies, H. M., Du Bois, J., and Yu, J.-Q. (2011). C-H Functionalization in organic synthesis. Chem Soc Rev, 40: $1855-1856$

14. Herbst, W., and Hunger, K. (2006). Industrial organic pigments: production, properties, applications. Hoboken, New Jersey: John Wiley \& Sons.

15. Hermanson, G. T. (2013). Bioconjugate techniques. Cambridge: Academic press.

16. Shenai, V. (1973). Chemistry of dyes and principles of dyeing. Bombay: Sevak Publications.

17. Hunger, K. (2007). Industrial dyes: chemistry, properties, applications. Hoboken, New Jersey: John Wiley \& Sons.

18. Kumar, R., Dayal, R., and Onial, P. (2014). Utilization of Tagetes minuta Aerial Parts as a Source of Natural Dyes for Textile Coloration. Waste Biomass Valori, 5: 699-707.

19. Kasiri, M., and Safapour, S. (2015). Exploring and exploiting plants extracts as the natural dyes/antimicrobials in textiles processing. Prog Color, Colorants Coat, 8: 87-114.

20. Samanta, A. K., and Konar, A. (2011). Dyeing of textiles with natural dyes. In Natural dyes: InTech

21. Yusuf, M., Shabbir, M., and Mohammad, F. (2017). Natural colorants: historical, processing and sustainable prospects. Nat Prod Bioprospect, 7: 123-145.

22. Mansour, H. (2013). Textile dyeing: Environmental friendly osage orange extract on protein fabrics. In EcoFriendly Textile Dyeing and Finishing. InTech.

23. Wipplinger, M. (2005). Natural dye instruction booklet. Seattle, Washington: Earthues.

24. Liles, J. N. (1990). The art and craft of natural dyeing: traditional recipes for modern use. Knoxville, Tennessee: Univ. of Tennessee Press.

25. Storey, J. (1992). The Thames and Hudson manual of dyes and fabrics. New York: Thames \& Hudson, Inc.

26. Trotman, E. (1970). Dyeing and Chemical Technology of Textile Fibres. London: Charles Griffin and 
Company Ltd.

27. Simpson, L. P., and Koester, A. W. (1995). Dyeing and colorfastness in fabrics. Corvallis, Or.: Extension Service, Oregon State University.

28. Wahl, G.H. (1990). Micro-scale Experiments in Organic Chemistry. Raleigh: North Carolina State University.

29. Raman, K. (2016). HPLC: Biochemical Analysis. A Step-By-Step Method Guide - SciGine. [online] SciGine. Available at: http://www.scigine.com/blog/hplc-analysis-method-guide/ [Accessed 6 Jan. 2018].

30. Gupta, Y., and Bhandari, K. (1975). Essential oil from the leaves of Tagetes minuta. Indian Perfum, 19: 2932.

31. Baslas, R., and Singh, A. (1981). Chemical examination of essential oil from the leaves of Tagetes-erecta Linn. J Indian Chem Soc, 58: 104.

32. Downum, K., and Towers, G. (1983). Analysis of thiophenes in the Tageteae (Asteraceae) by HPLC. J Nat Prod, 46: 98-103.

33. Tripathy, A., and Gupta, K. (1991). Plant phenolics of Tagetes erecta. Fitoterapia, 62: 91-92.

34. Oger, B. (1996). Fastness to light and washing of direct dyes for cellulosic textiles. Stud Conserv, 41: 129135.

35. Arora, J., Agarwal, P., and Gupta, G. (2017). Rainbow of Natural Dyes on Textiles Using Plants Extracts: Sustainable and Eco-Friendly Processes. Green and Sustainable Chemistry, 7: 35.

36. Bechtold, T., Turcanu, A., Ganglberger, E., and Geissler, S. (2003). Natural dyes in modern textile dyehouseshow to combine experiences of two centuries to meet the demands of the future? J Clean Prod, 11: 499-509.

37. Shahid, M., and Mohammad, F. (2013). Recent advancements in natural dye applications: a review. J Clean Prod, 53: 310-331. 